\title{
Association of Family History With Cancer Recurrence, Survival, and the Incidence of Colorectal Adenoma in Patients With Colorectal Cancer
}

\author{
Yehyun Park ${ }^{1}$, Soo Jung Park ${ }^{1}$, Jae Hee Cheon ${ }^{1}$, Won Ho Kim ${ }^{1}$, Tae II Kim ${ }^{1,2,3}$ \\ ${ }^{1}$ Department of Internal Medicine and Institute of Gastroenterology, Yonsei University College of Medicine, ${ }^{2}$ Cancer Prevention Center, Yonsei \\ Cancer Center, ${ }^{3}$ Brain Korea 21 PLUS Project for Medical Science, Yonsei University College of Medicine, Seoul, Korea
}

\begin{abstract}
Background: The influence of family history (FH) on cancer recurrence and survival among patients with established colorectal cancer (CRC) remains uncertain. This study aimed to evaluate the association of FH with cancer recurrence, survival, and the incidence of colorectal adenomas in patients with CRC.

Methods: Consecutive patients with stage III CRC diagnosed between 2004 and 2009 and followed-up in Severance Hospital were retrospectively enrolled and followed until December 2014. Overall survival (OS) and disease-free survival (DFS) according to FH of CRC or colorectal neoplasm were evaluated using Cox proportional hazards regression and Kaplan-Meier curve.

Results: Among analyzed 979 patients, 69 (7.0\%) was identified as having a FH of CRC in a first-degree relative. During a median follow-up of 9.6 years, mortality occurred in 14 of 69 patients (20.3\%) with a FH of CRC and 348 of 910 patients (38.2\%) without a FH. Compared with patients without a FH, a first-degree FH of CRC, first or second-degree FH of CRC, and first-degree FH of colorectal neoplasm (CRC or polyps) were associated with a significant reduction in the risk of overall mortality, with adjusted hazard ratios (HRs) of $0.52(95 \% \mathrm{Cl}, 0.29-0.92), 0.51(95 \% \mathrm{Cl}, 0.30-0.88)$, and $0.48(95 \% \mathrm{Cl}, 0.28-0.82)$, respectively. However, DFS improvement was significant only when the definition of $\mathrm{FH}$ was $\mathrm{FH}$ of colorectal neoplasm (adjusted HR $0.57 ; 95 \% \mathrm{Cl}, 0.36-0.89$ ). The incidence of adenoma and advanced adenoma was not different according to the FH.

Conclusions: Among patients with stage III CRC receiving curative surgery, a FH of colorectal neoplasm was associated with a reduction in cancer recurrence and mortality. The larger scaled studies are needed.
\end{abstract}

(J Cancer Prev 2019;24:1-10)

Key Words: Colorectal cancer, Family, Survival, Adenoma

\section{INTRODUCTION}

Approximately $5 \%$ to $10 \%$ of colorectal cancer (CRC) patients have at least one affected first-degree relative (FDR) with CRC $[1,2]$. Having a family history $(\mathrm{FH})$ of CRC in a FDR is a known risk factor for the development of CRC, with twofold increased lifetime risk of CRC [3-5]. This risk increases with a greater number or younger age at diagnosis of the affected FDRs [6-8]. Based on this, current screening recommendations for CRC adopted the number and age at diagnosis above or below 60 years of affected FDR with CRC or an advanced adenoma as risk stratifiers [9].

However, the influence of FH of CRC on CRC recurrence and survival remains uncertain, and the results from studies are inconsistent. Several studies reported the negligible impact of $\mathrm{FH}$ of CRC and survival [10-12]. Some studies reported improved survival [13-16], whereas the others showed worse prognosis in patients with a FH of CRC $[17,18]$. This inconsistency may be attributed to different study designs, heterogeneity in baseline CRC characteristics and study population, or different definition

Received March 20, 2019, Accepted March 21, 2019

Correspondence to: Tae Il Kim

E-mail: taeilkim@yuhs.ac, ORCID: Tae Il Kim, https://orcid/org/0000-0003-4807-890X

Copyright (C) 2019 Korean Society of Cancer Prevention

(c) This is an Open Access article distributed under the terms of the Creative Commons Attribution Non-Commercial License (http://creativecommons.org/licenses/by-nc/4.0) which permits unrestricted non-commercial use, distribution, and reproduction in any medium, provided the original work is properly cited. 
of FH. The definition of FH among patients with CRC can vary, from including only FDR with CRC to encompassing second- or third-degree relatives with $\mathrm{CRC}$ or adenomas. These various definitions of $\mathrm{FH}$ were not applied or compared in previous studies evaluating outcome in CRC patients with FH, and it is unknown which definition has the largest association with the prognosis.

A FH of CRC is often the cause of shorter colonoscopy surveillance interval, although the rationale is insufficient [19]. The influence of $\mathrm{FH}$ on the recurrence or survival of $\mathrm{CRC}$ has been studied, but no study has evaluated the impact of $\mathrm{FH}$ on the incidence of colorectal adenomas on follow-up surveillance colonoscopy in patients with previous $\mathrm{CRC}$. One study showed that individuals with an FH of FDR with CRC were more likely to have a recurrence of adenomas, but this was not statistically significant [20]. Currently it is unknown whether a FH of CRC would impact the natural history of adenoma, especially in patients with previous CRC, and whether consideration of shorter surveillance interval is needed in patients with previous $\mathrm{CRC}$ and $\mathrm{FH}$.

The aim of our study was to evaluate the association of $\mathrm{FH}$ of CRC with cancer recurrence, survival, and the incidence of colorectal adenomas in patients with stage III CRC through the use of a various definitions of $\mathrm{FH}$ and more homogenous Asian patients.

\section{MATERIALS AND METHODS}

\section{Study population}

Consecutive patients with stage III CRC diagnosed between 2004 and 2009 and followed-up in Severance Hospital were retrospectively enrolled and followed until October 2018. Exclusion criteria were incomplete records including $\mathrm{FH}$, not receiving curative surgery, patients with known familial adenomatous polyposis or hereditary nonpolyposis CRC (HNPCC), and inflammatory bowel disease.

The study protocol was in accordance with the ethics guidelines of the 1975 Declaration of Helsinki and the study procedure was approved by the Institutional Review Board of Severance Hospital.

\section{Data collection and family history assessment}

Demographics and medical history, FH of CRC or adenoma were obtained by medical chart review. Multiple medical records containing FH status such as admission note, intern note, nurse chart, and colonoscopy results were reviewed. Survival or death, along with the cause of death was confirmed by data from
National Cancer Registry. We used three different definitions of FH: 1) first-degree FH of CRC, which was defined as having at least one FDR (parent, sibling, or offspring) with CRC; 2) first or second-degree FH of CRC, which was defined as having at least one first-degree or second-degree relative with $\mathrm{CRC}$; 3) first-degree $\mathrm{FH}$ of colorectal neoplasm (CRC or polyps), which is defined as having at least one FDR with CRC or colorectal polyps.

\section{Colonoscopic surveillance}

All patients received a baseline colonoscopy before curative surgery or within 6 months after the surgery (in cases of obstructing CRCs). We excised all adenomas detected during baseline colonoscopy. The incidence of colorectal adenoma and advanced adenoma in each surveillance colonoscopy and during total follow-up period was evaluated. An advanced adenoma was defined as an adenoma $10 \mathrm{~mm}$ or greater in diameter, an adenoma with villous component, or with high-grade dysplasia or carcinoma.

\section{Survival analysis}

The endpoints were overall survival (OS), disease-free survival (DFS), and colorectal adenoma incidence rate on each surveillance colonoscopy. OS was defined as the time from initial curative surgery to death as a result of any cause. DFS was defined as the time from initial curative surgery to tumor recurrence, occurrence of a new primary CRC, or death from any cause. Colorectal adenoma incidence rate was defined as the number of patients with adenoma in surveillance colonoscopy divided by total number of patients with surveillance colonoscopy.

\section{Statistical analysis}

Baseline patient characteristics were analyzed with descriptive statistics. Comparisons of demographic, clinical, and pathologic variables according to the $\mathrm{FH}$ were done using Student's t-test for continuous variables and Pearson's $\chi^{2}$ test for categorical variables. The survival analysis was done using Kaplan-Meier curves and the log-rank test. Cox proportional hazards regression was used to determine the simultaneous impact of $\mathrm{FH}$ and potential confounders on OS and DFS. Tests of interactions between $\mathrm{FH}$ and potentially modifying covariates were assessed by entering the cross product of $\mathrm{FH}$ and the covariate of interest. A logistic regression analysis was used to evaluate the colorectal adenoma incidence rate with adjustment for various confounders.

A value of $P<0.05$ was considered significant. All statistical analyses were conducted using IBM SPSS ver. 20.0 (IBM Corp., Armonk, NY, USA). 


\section{RESULTS}

\section{Baseline and follow-up characteristics}

Figure 1 shows a flowchart of the study. Of 1,001 consecutive patients with stage III CRC diagnosed between 2004 and 2009 and followed-up in Severance Hospital, 979 patients were included in analysis. Baseline characteristics for the 979 patients are presented in Table 1. Among analyzed 979 patients, 69 (7.0\%) was identified as having a FH of CRC in at least one FDR. A total of 79 (8.1\%) had a FH of CRC in at least one FDR or second-degree relative, and 87 (8.9\%) had at least one FDR with CRC or colorectal polyps. The baseline characteristics and potentially prognostic patient and tumor characteristics were not different according to FH. Microsatellite instability (MSI) measurement was performed in 880 (89.9\%) of 979 patients, and the results were not different according to the $\mathrm{FH}$ (Table 1).

The median follow-up time from curative surgery was 9.6 years (interquartile range, 4.9-10.9 years). Mortality occurred in 14 of 69 patients (20.3\%) with a FH of CRC in at least one FDR and 348 of 910 patients (38.2\%) without a $\mathrm{FH}$.

\section{Survival analysis}

A FH of CRC was associated with a significant reduction in the risk of cancer recurrence or overall mortality (Fig. 2 and 3). This improvement in OS and DFS was consistent among different definitions of $\mathrm{FH}$, and this relationship remained largely unchanged after adjusting for other predictors of survival (Table 2 and 3). The results from univariate and multivariate Cox regression analyses of predictors of OS and DFS are shown in Table 2. Along with age at diagnosis (hazard ratio [HR] 1.03; 95\% CI, 1.02-1.04), performance status (HR 1.48; 95\% CI, 1.16-1.90), number of positive lymph nodes (HR 1.64; 95\% CI, 1.31-2.06) and adjuvant chemotherapy (HR 0.67; 95\% CI, 0.49-0.93), FH of colorectal neoplasm was independent favorable predictor for OS

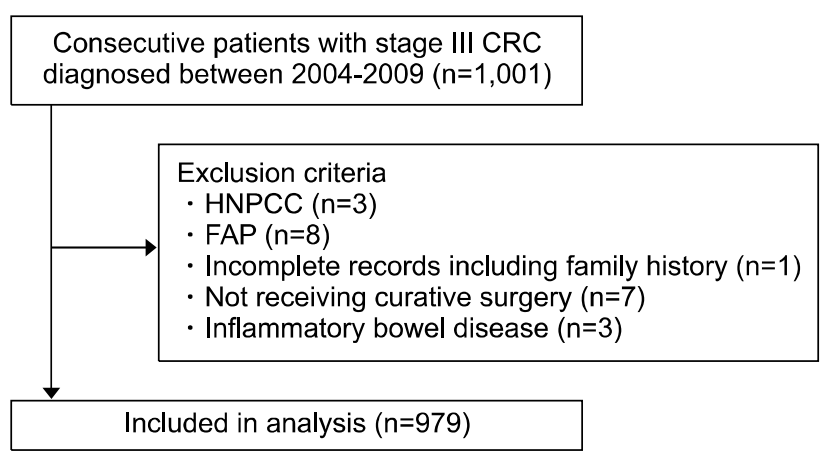

Figure 1. Flowchart of the study. CRC, colorectal cancer; HNPCC, hereditary nonpolyposis CRC; FAP, familial adenomatous polyposis. (multivariable adjusted HR 0.49; 95\% CI, 0.28-0.83). The adjusted HR was 0.52 (95\% CI, 0.29-0.92) and 0.51 (95\% CI, 0.30-0.88) when using the definition of $\mathrm{FH}$ of 'CRC in FDR' and 'CRC in FDR or second-degree relative', respectively. However, the adjusted HR for cancer recurrence or death (i.e., DFS) was significant only when the definition of FH was 'colorectal neoplasm in FDR' (HR of 0.57; 95\% CI, 0.36-0.89).

We also assessed the association between FH and OS or DFS according to the strata of other potential predictors of outcome (Fig. 4). Because FH definition of 'colorectal neoplasm in FDR' was consistently significant predictor for both OS and DFS, we used this definition of FH in stratified analysis. The effect of FH on the risk of cancer recurrence or death was not significantly modified by gender or performance status. In contrast, the effect of FH was

Table 1. Baseline characteristics by family history of colorectal cancer

\begin{tabular}{|c|c|c|c|}
\hline \multirow{2}{*}{ Characteristic } & \multicolumn{2}{|c|}{$\begin{array}{l}\text { First-degree family history } \\
\text { of colorectal cancer }\end{array}$} & \multirow{2}{*}{$P$-value } \\
\hline & No $(\mathrm{n}=910)$ & Yes $(n=69)$ & \\
\hline Age (yr) & $59.7(14-90)$ & $57.5(34-75)$ & 0.14 \\
\hline Sex (male) & $557(61.2)$ & $37(53.6)$ & 0.21 \\
\hline Body mass index $\left(\mathrm{kg} / \mathrm{m}^{2}\right)$ & $23.5(15.8-37.0)$ & $23.5(17.7-31.0)$ & 0.29 \\
\hline ECOG PS & & & 0.21 \\
\hline 0 & $749(79.5)$ & $54(77.1)$ & \\
\hline $1-2$ & $193(20.5)$ & $16(22.9)$ & \\
\hline Current smoking & $133(14.6)$ & $12(17.4)$ & 0.53 \\
\hline Alcohol & & & 0.71 \\
\hline None & $601(66.3)$ & $45(65.2)$ & \\
\hline$<1 \mathrm{drink} / \mathrm{d}$ & $249(27.5)$ & $18(26.1)$ & \\
\hline$\geq 1 \mathrm{drink} / \mathrm{d}$ & $56(6.2)$ & $6(8.7)$ & \\
\hline Site of primary tumor & & & 0.23 \\
\hline Right colon & $194(21.3)$ & $19(27.5)$ & \\
\hline Left colon and rectum & $716(78.7)$ & $50(72.5)$ & \\
\hline Preoperative CEA (ng/mL) & $3.00(0-259)$ & $2.00(0-294)$ & 0.61 \\
\hline Depth of invasion throug & gh bowel wall & & 0.15 \\
\hline $\mathrm{T} 1$ and $\mathrm{T} 2$ & $105(11.5)$ & $12(17.4)$ & \\
\hline $\mathrm{T} 3$ and $\mathrm{T} 4$ & $805(88.5)$ & $57(82.6)$ & \\
\hline Positive lymph nodes & & & 0.25 \\
\hline $1-3$ & $611(67.1)$ & $51(73.9)$ & \\
\hline$\geq 4$ & $299(32.9)$ & $18(26.1)$ & \\
\hline Tumor differentiation & & & 0.86 \\
\hline Well & $89(9.8)$ & $7(10.1)$ & \\
\hline Moderate & $730(80.2)$ & $54(78.3)$ & \\
\hline Poor & $53(5.8)$ & $4(5.8)$ & \\
\hline Other & $38(4.2)$ & $4(5.8)$ & \\
\hline MSI status & & & 0.08 \\
\hline MSS & $756(92.6)$ & $55(85.9)$ & \\
\hline MSI-L & $34(4.2)$ & $4(6.2)$ & \\
\hline MSI-H & $26(3.2)$ & $5(7.8)$ & \\
\hline
\end{tabular}

Values are presented as median (range) or number (\%). ECOG, Eastern Cooperative Oncology Group; PS, performance status; CEA, carcinoembryonic antigen; MSI, microsatellite instability; MSS, microsatellite stable; MSI-L, MSI-low; MSI-H, MSI-high. 

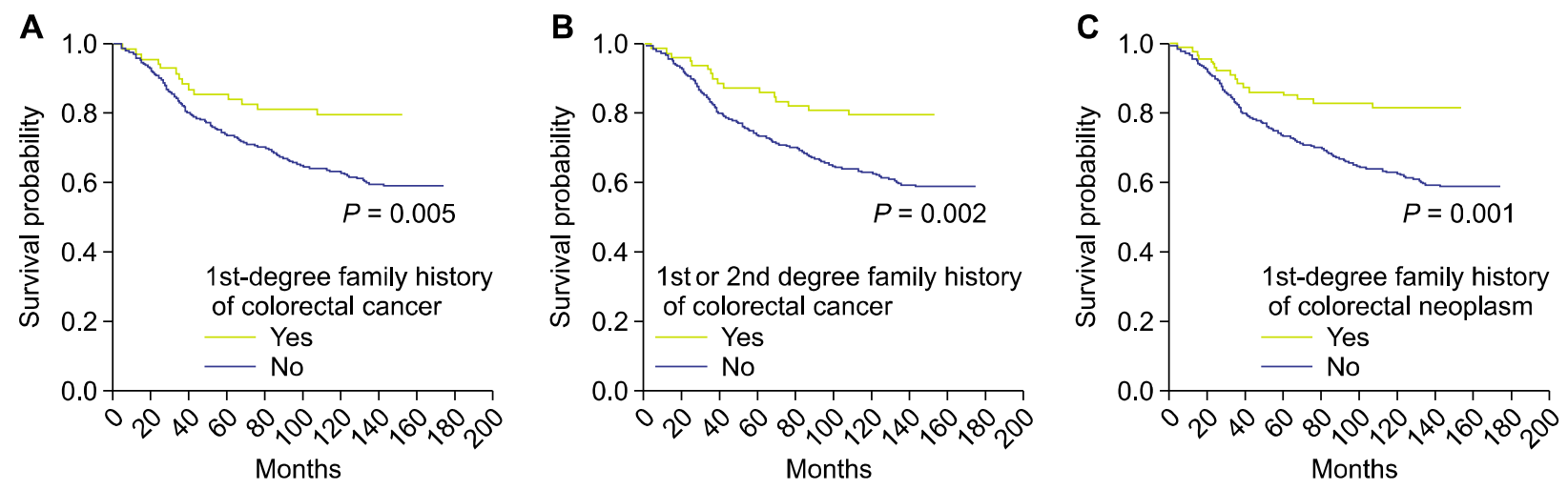

Figure 2. Overall survival according to the different definitions of family history in stage III colorectal cancer ( $\mathrm{n}=979$ ). (A) Overall survival according to 1st-degree family history of colorectal cancer. (B) Overall survival according to 1st or 2nd degree family history of colorectal cancer. (C) Overall survival according to 1st-degree family history of colorectal cancer or polyp.
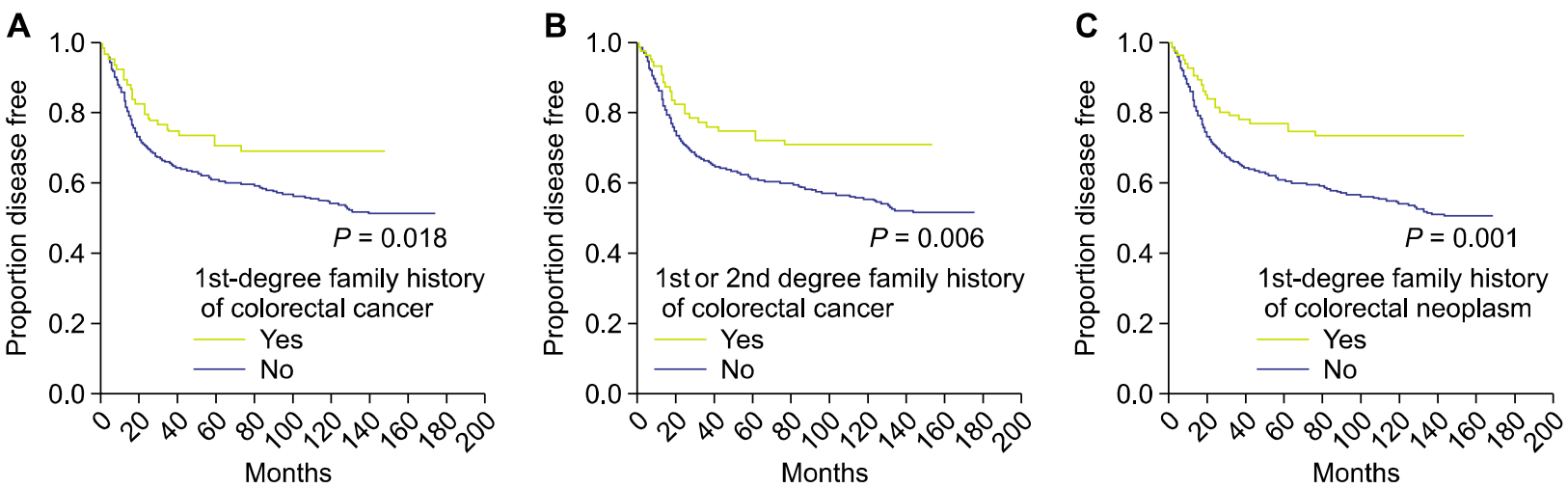

Figure 3. Disease-free survival according to the different definitions of family history in stage III colorectal cancer $(n=979)$. (A) Disease-free survival according to 1st-degree family history of colorectal cancer. (B) Disease-free survival according to 1st or 2nd degree family history of colorectal cancer. (C) Disease-free survival according to 1st-degree family history of colorectal cancer or polyp.

different according to patient age, depth of invasion, number of positive lymph nodes, tumor location, differentiation, and MSI status. The protective effect of $\mathrm{FH}$ of colorectal neoplasm on cancer recurrence or mortality was prominent among patients older than 50 years, T3 or T4 disease, positive lymph node of less than 4, tumor location at left colon (splenic flexure to the rectosigmoid junction) and rectum, well to moderate differentiation, and microsatellite stable (MSS) tumor. However, a test of interaction between these factors and the presence of $\mathrm{FH}$ revealed that the effect of $\mathrm{FH}$ on OS and DFS did not appear to be modified by these factors (all $P$ for interaction $>0.05$ ) (Fig. 4).

\section{Colonoscopic surveillance and findings of follow-up colonoscopy}

Among the 637 patients underwent follow-up colonoscopy in our hospital, 226 (35.5\%), 360 (56.5\%), and 51 patients (8.0\%) underwent follow-up colonoscopy once, twice, and more than three times, respectively. More follow-up colonoscopies were done in patients with $\mathrm{FH}$ with colorectal neoplasm than patients without $\mathrm{FH}(P<0.01)$. Also, the interval to the first follow-up colonoscopy was slightly shorter in patients with $\mathrm{FH}(13.8 \mathrm{mo}$ vs. $13.4 \mathrm{mo}, P=0.03$ ) (Table 4). The incidence of adenoma and advanced adenoma in each follow-up colonoscopy and during entire follow-up was evaluated. There was no difference in detection of total adenoma or advanced adenoma in subjects with FH compared to those without FH (OR 1.27 and 1.33, all $P>0.05$ ) (Table 5). This was unchanged after adjustment for potential factors related to the adenoma and advanced adenoma incidence, including age, gender, BMI, number of follow-up colonoscopies, MSI status, aspirin use, metformin use, interval to first follow-up colonoscopy, and chemotherapy (Supplementary Table S1). For advanced adenoma, MSI was related to the incidence of advanced adenoma (adjusted OR 3.34; 95\% CI, 1.31-8.53). 
Table 2. Univariate and multivariate analysis for overall survival and disease-free survival in patients with stage III colorectal cancer

\begin{tabular}{|c|c|c|c|c|c|c|}
\hline \multirow{2}{*}{ Characteristic } & \multicolumn{3}{|c|}{ Univariate analysis } & \multicolumn{3}{|c|}{ Multivariate } \\
\hline & Hazard ratio & $95 \% \mathrm{CI}$ & $P$-value & Hazard ratio & $95 \% \mathrm{CI}$ & $P$-value \\
\hline \multicolumn{7}{|l|}{ Overall survival } \\
\hline 1st-degree family history of $\mathrm{CRC}^{\mathrm{a}}$ & 0.48 & $0.28-0.82$ & $<0.01$ & 0.52 & $0.29-0.92$ & 0.03 \\
\hline 1st or 2nd-degree family history of $\mathrm{CRC}^{\mathrm{a}}$ & 0.47 & $0.28-0.77$ & $<0.01$ & 0.51 & $0.30-0.88$ & 0.02 \\
\hline 1st-degree family history of colorectal neoplasm ${ }^{a}$ & 0.42 & $0.26-0.70$ & $<0.01$ & 0.48 & $0.28-0.82$ & 0.01 \\
\hline Age & 1.04 & $1.03-1.05$ & $<0.01$ & 1.03 & $1.02-1.04$ & $<0.01$ \\
\hline Male sex & 1.22 & $0.98-1.51$ & 0.08 & & & \\
\hline BMI & 0.96 & $0.93-0.99$ & 0.01 & 0.97 & $0.94-1.01$ & 0.14 \\
\hline Current smoking & 1.16 & $0.88-1.53$ & 0.30 & & & \\
\hline Alcohol & & & 0.35 & & & \\
\hline None & 1 & & & & & \\
\hline$<1$ drink/d & 0.86 & $0.68-1.10$ & 0.22 & & & \\
\hline$\geq 1 \mathrm{drink} / \mathrm{d}$ & 0.86 & $0.55-1.34$ & 0.50 & & & \\
\hline Performance status (0 vs. $1-2$ ) & 1.58 & $1.25-1.99$ & $<0.01$ & 1.48 & $1.16-1.90$ & $<0.01$ \\
\hline Depth of invasion ( $\mathrm{T} 1$ and $\mathrm{T} 2$ vs. $\mathrm{T} 3$ and $\mathrm{T} 4$ ) & 1.49 & $1.04-2.14$ & 0.03 & 1.26 & $0.88-1.81$ & 0.22 \\
\hline Positive lymph nodes (1-3 vs. $\geq 4$ ) & 1.70 & $1.38-2.10$ & $<0.01$ & 1.64 & $1.31-2.06$ & $<0.01$ \\
\hline Right colon & 1.07 & $0.84-1.38$ & 0.58 & & & \\
\hline Preoperative CEA & 1.00 & $1.00-1.01$ & 0.12 & & & \\
\hline Poor differentiation & 1.63 & $1.01-2.41$ & 0.02 & 1.47 & $0.98-2.19$ & 0.06 \\
\hline MSI status & & & 0.29 & & & \\
\hline MSS & 1 & & & & & \\
\hline MSI-L & 1.06 & $0.62-1.81$ & 0.831 & & & \\
\hline MSI-H & 0.49 & $0.22-1.10$ & 0.09 & & & \\
\hline Adjuvant chemotherapy & 0.54 & $0.41-0.72$ & $<0.01$ & 0.67 & $0.49-0.93$ & 0.02 \\
\hline \multicolumn{7}{|l|}{ Disease-free survival } \\
\hline 1st-degree family history of $\mathrm{CRC}^{\mathrm{a}}$ & 0.59 & $0.38-0.92$ & 0.02 & 0.68 & $0.42-1.09$ & 0.11 \\
\hline 1st or 2nd-degree family history of $\mathrm{CRC}^{\mathrm{a}}$ & 0.56 & $0.37-0.85$ & 0.01 & 0.65 & $0.41-1.02$ & 0.65 \\
\hline 1st-degree family history of colorectal neoplasm ${ }^{a}$ & 0.49 & $0.33-0.75$ & $<0.01$ & 0.57 & $0.36-0.89$ & $<0.01$ \\
\hline Age & 1.02 & $1.02-1.03$ & $<0.01$ & 1.02 & $1.01-1.03$ & $<0.01$ \\
\hline Male sex & 1.20 & $0.99-1.46$ & 0.06 & & & \\
\hline BMI & 0.97 & $0.94-1.00$ & 0.04 & 0.97 & $0.94-1.00$ & 0.09 \\
\hline Current smoking & 1.23 & $0.95-1.57$ & 0.11 & & & \\
\hline Alcohol & & & 0.83 & & & \\
\hline None & 1 & & & & & \\
\hline$<1$ drink $/ \mathrm{d}$ & 0.99 & $0.80-1.23$ & 0.96 & & & \\
\hline$\geq 1 \mathrm{drink} / \mathrm{d}$ & 0.88 & $0.59-1.32$ & 0.54 & & & \\
\hline Performance status (0 vs. $1-2$ ) & 1.50 & $1.21-1.86$ & $<0.01$ & 1.36 & $1.07-1.72$ & $<0.01$ \\
\hline Depth of invasion ( $\mathrm{T} 1$ and $\mathrm{T} 2$ vs. $\mathrm{T} 3$ and $\mathrm{T} 4$ ) & 1.67 & $1.20-2.32$ & $<0.01$ & 1.39 & $0.97-1.99$ & 0.07 \\
\hline Positive lymph nodes (1-3 vs. $\geq 4$ ) & 1.67 & $1.38-2.02$ & $<0.01$ & 1.52 & $1.22-1.88$ & $<0.01$ \\
\hline Right colon & 1.02 & $0.81-1.28$ & 0.90 & & & \\
\hline Preoperative CEA & 1.00 & $1.00-1.01$ & 0.04 & 1.01 & $1.00-1.01$ & $<0.01$ \\
\hline Poor differentiation & 1.74 & $1.23-2.47$ & $<0.01$ & 1.91 & $1.31-2.77$ & $<0.01$ \\
\hline MSI status & & & 0.17 & & & \\
\hline MSS & 1 & & & & & \\
\hline MSI-L & 0.90 & $0.54-1.52$ & 0.70 & & & \\
\hline MSI-H & 0.51 & $0.25-1.03$ & 0.06 & & & \\
\hline Adjuvant chemotherapy & 0.73 & $0.55-0.97$ & 0.03 & 0.91 & $0.65-1.29$ & 0.61 \\
\hline
\end{tabular}

CRC, colorectal cancer; BMI, body mass index; CEA, carcinoembryonic antigen; MSI, microsatellite instability; MSS, microsatellite stable; MSI-L, MSI-low; MSI-H, MSI-high. ${ }^{a}$ Each different definition of family history was included in mutivariate analysis separately. Among three separate multivariate analyses according to the different definitions of family history, hazard ratios and $P$-values with '1st-degree family history of colorectal neoplasm' were expressed. 


\section{DISCUSSION}

In the present study, a FH of colorectal neoplasm in FDR was associated with a significant reduction in cancer recurrence and mortality in a cohort of patients with stage III CRC treated with surgery. This improvement in OS and DFS was consistent among

Table 3. Unadjusted and multivariate adjusted hazard ratios for overall survival and disease-free survival according to presence of family member with colorectal neoplasm

\begin{tabular}{|c|c|c|c|c|c|c|}
\hline \multirow{2}{*}{ Variable } & \multicolumn{2}{|c|}{ 1st-degree $\mathrm{FH}$ of CRC } & \multicolumn{2}{|c|}{ 1st or 2nd-degree $\mathrm{FH}$ of $\mathrm{CRC}$} & \multicolumn{2}{|c|}{ 1st-degree $\mathrm{FH}$ of colorectal neoplasm } \\
\hline & No & Yes & No & Yes & No & Yes \\
\hline \multicolumn{7}{|l|}{ Overall mortality } \\
\hline No. of events & 348 & 14 & 346 & 16 & 346 & 16 \\
\hline No. at risk & 910 & 69 & 900 & 79 & 892 & 87 \\
\hline Unadjusted HR (95\% CI) & 1 & $0.48(0.28-0.82)$ & 1 & $0.47(0.28-0.77)$ & 1 & $0.42(0.26-0.70)$ \\
\hline Adjusted HR (95\% CI) & 1 & $0.52(0.29-0.92)$ & 1 & $0.59(0.32-1.07)$ & 1 & $0.49(0.28-0.83)$ \\
\hline \multicolumn{7}{|c|}{ Cancer recurrence or death from any cause (disease-free survival) } \\
\hline No. of events & 419 & 21 & 417 & 23 & 417 & 23 \\
\hline No. at risk & 910 & 69 & 900 & 79 & 892 & 87 \\
\hline Unadjusted HR (95\% CI) & 1 & $0.59(0.38-0.92)$ & 1 & $0.56(0.37-0.85)$ & 1 & $0.49(0.33-0.75)$ \\
\hline Adjusted HR (95\% CI) & 1 & $0.68(0.42-1.09)$ & 1 & $0.65(0.41-1.02)$ & 1 & $0.57(0.36-0.91)$ \\
\hline
\end{tabular}

FH, family history; CRC, colorectal cancer; HR, hazard ratio.

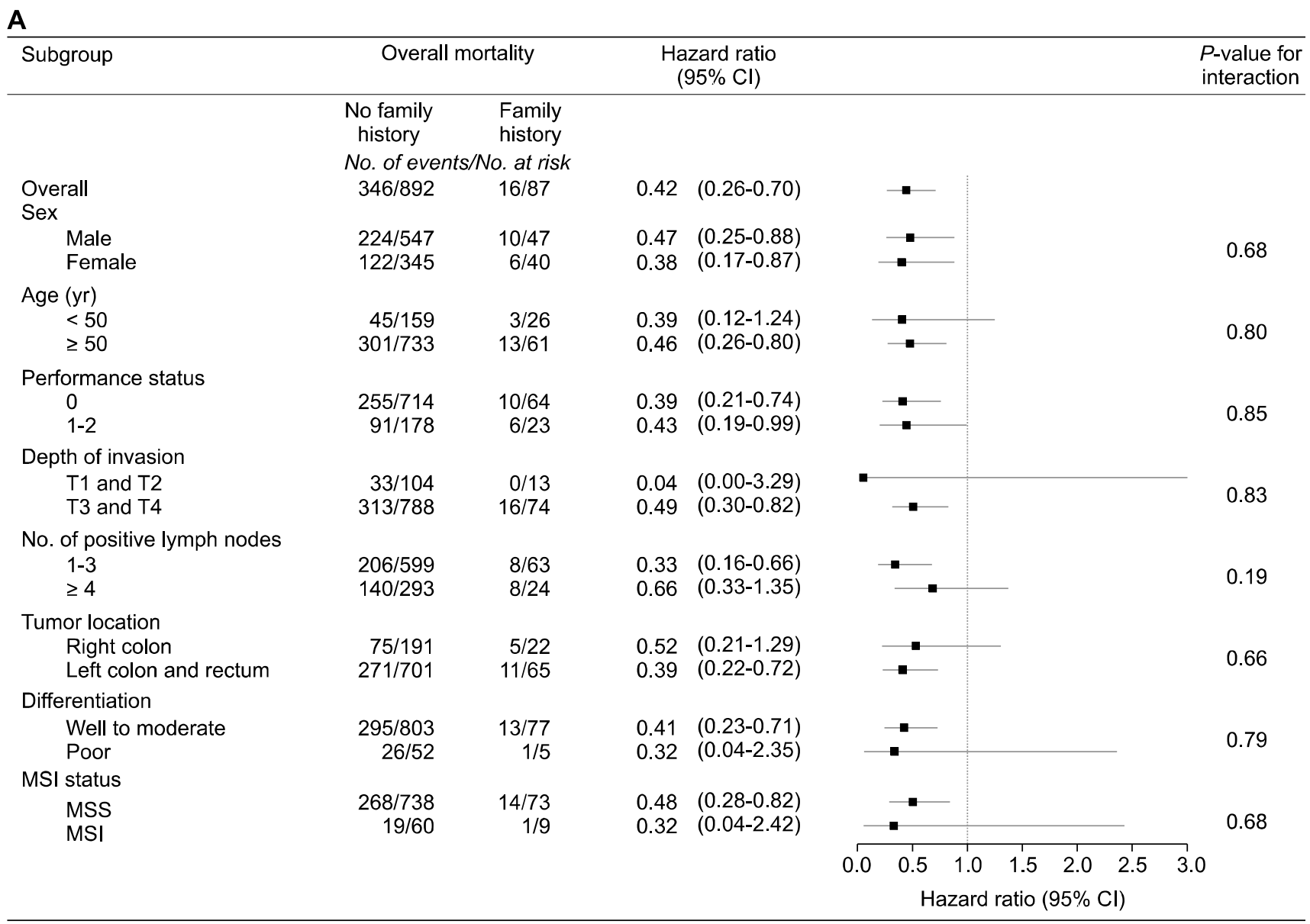

Figure 4. Stratified analysis of overall survival (A) and disease-free survival (B) according to the 1st-degree family history of colorectal neoplasm. MSI, microsatellite instability; MSS, microsatellite stable. 
B

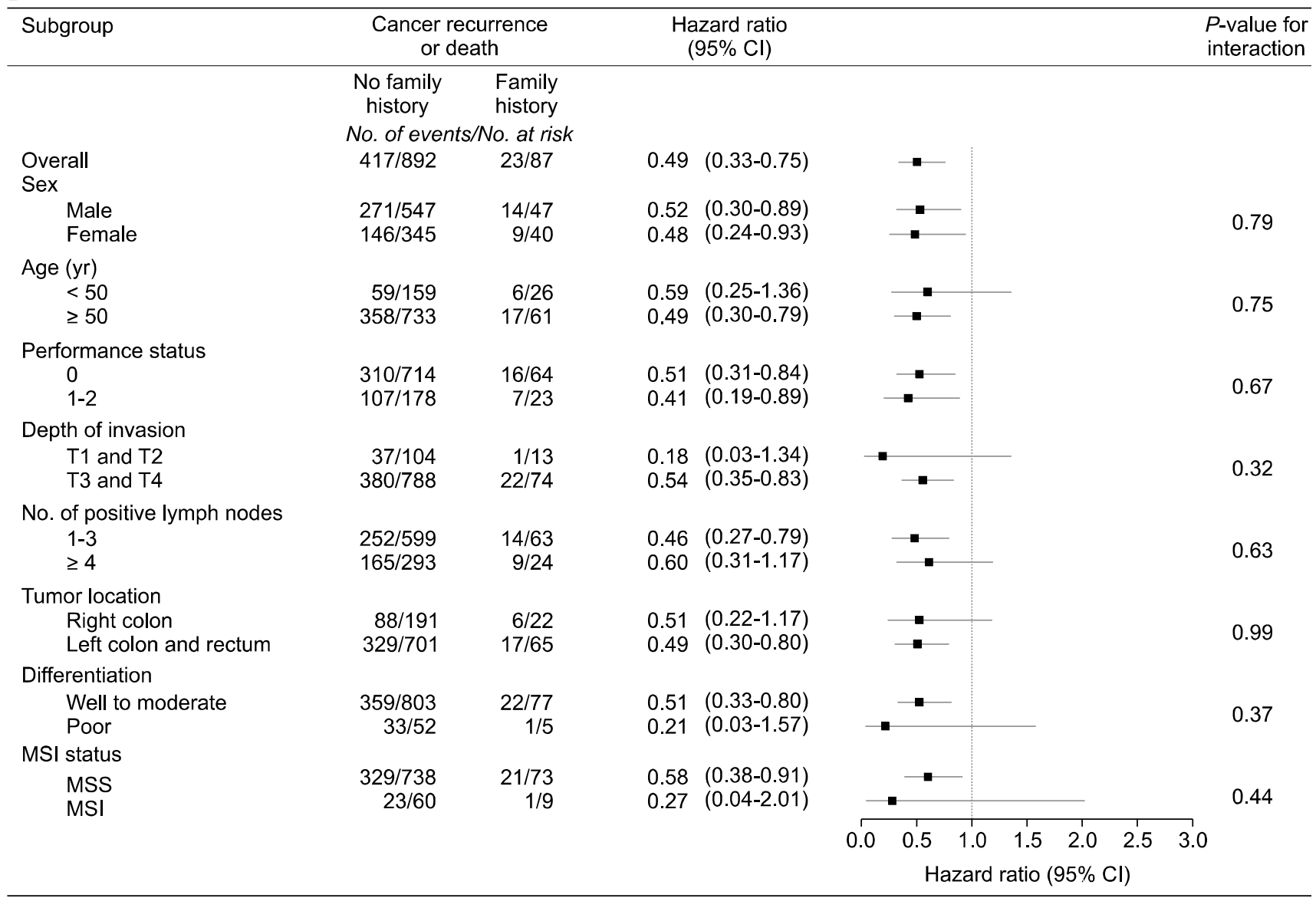

Figure 4. Continued.

Table 4. Comparison of total number and interval of follow-up colonoscopies between the patients with and without family history of colorectal neoplasm

\begin{tabular}{cccc}
\hline \multicolumn{1}{c}{$\begin{array}{c}\text { No family history } \\
(\mathrm{n}=565)\end{array}$} & $\begin{array}{c}\text { Family history } \\
(\mathrm{n}=72)\end{array}$ & $P$-value \\
\hline No. of follow-up colonoscopies & & 0.01 \\
1 & $210(37.2)$ & $16(22.2)$ & \\
2 & $315(55.8)$ & $45(62.5)$ & \\
$\geq 3$ & $40(7.1)$ & $11(15.3)$ & \\
Interval to follow-up colonoscopy (mo) & & \\
1st & $13.8(3.6-93.9)$ & $13.4(3.8-40.7)$ & 0.03 \\
2nd & $48(17-72)$ & $48(23-59)$ & 0.41 \\
3rd & $81(36-110)$ & $78(51-94)$ & 0.57 \\
\hline
\end{tabular}

Values are presented as number (\%) or median (range).

different definitions of $\mathrm{FH}$, but the adjusted HR for cancer recurrence or death was significant only when the definition of FH was 'colorectal neoplasm in FDR'. The incidence of adenoma and advanced adenoma during surveillance colonoscopy was not different according to the $\mathrm{FH}$.
The originality of this study is as follows. First, we addressed the influence of $\mathrm{FH}$ on the prognosis of patients with CRC using various definitions of $\mathrm{FH}$, and found that the $\mathrm{FH}$ of colorectal neoplasm including CRC and polyps is associated with reduced recurrence and mortality of CRC. Second, we evaluated whether a $\mathrm{FH}$ of colorectal neoplasm would impact the natural history of adenoma in patients with previous CRC and found that the incidence of adenomas and advanced adenomas was not different according to the $\mathrm{FH}$ of colorectal neoplasm in patients with CRC.

The definition of $\mathrm{FH}$ among patients with CRC can vary, and most studies define the FH as 'FH of CRC in FDR' with or without including second-degree relatives. Whether the $\mathrm{FH}$ of colorectal neoplasm including polyps in FDR affects the prognosis of patients with CRC is unknown. In this study, FH of not only CRC but also polyps in FDR had association with prognosis in patients with CRC. Although this finding needs to be confirmed by further studies, more detailed history taking including FH of colorectal polyps may be helpful in prognostication of CRC patients. 
Table 5. Comparison of the incidence rates of adenoma and advanced adenoma on each follow-up colonoscopy between the patients with and without family history of colorectal neoplasm

\begin{tabular}{|c|c|c|c|c|c|}
\hline Follow-up colonoscopy & No family history $(\mathrm{n}=565)$ & Family history $(\mathrm{n}=72)$ & OR & $95 \% \mathrm{CI}$ & $P$-value \\
\hline \multicolumn{6}{|l|}{ 1st } \\
\hline Adenoma incidence & $130 / 565(23.0)$ & $17 / 72(23.6)$ & 1.41 & $0.85-2.34$ & 0.19 \\
\hline Advanced adenoma incidence & $22 / 565(3.9)$ & $2 / 72(2.8)$ & 1.18 & $0.27-5.12$ & 0.82 \\
\hline \multicolumn{6}{|l|}{ 2nd } \\
\hline Adenoma incidence & $80 / 355(22.5)$ & $13 / 56(23.2)$ & 0.89 & $0.49-1.59$ & 0.68 \\
\hline Advanced adenoma incidence & $8 / 355(2.3)$ & $2 / 56(3.6)$ & 1.46 & $0.31-6.87$ & 0.63 \\
\hline \multicolumn{6}{|l|}{$3 r d$} \\
\hline Adenoma incidence & $13 / 40(32.5)$ & $5 / 10(50.0)$ & 2.94 & $0.97-8.91$ & 0.06 \\
\hline Advanced adenoma incidence & $2 / 40(5.0)$ & $1 / 10(10.0)$ & 2.91 & $0.26-32.65$ & 0.39 \\
\hline \multicolumn{6}{|l|}{ Total } \\
\hline Total adenoma & $181(32.0)$ & $27(37.5)$ & 1.27 & $0.76-2.11$ & 0.36 \\
\hline Advanced adenoma & $30(5.3)$ & $5(6.9)$ & 1.33 & $0.50-3.54$ & 0.57 \\
\hline
\end{tabular}

Values are presented as number (\%). OR, odds ratio.

We observed an increase in surveillance colonoscopy among those with a FH. Nevertheless, the incidence of adenoma and advanced adenoma was not increased in the patients with CRC having $\mathrm{FH}$ of colorectal neoplasm. It is unknown whether a FH of CRC would impact the natural history of adenoma, especially in patients with previous $\mathrm{CRC}$, but the need for more frequent surveillance colonoscopy in patients with previous $\mathrm{CRC}$ and $\mathrm{FH}$ has been a concern of many clinicians. In the clinical practice, a FH of CRC is often the cause of shorter colonoscopy surveillance interval, although the rationale is insufficient [19]. Although more results from prospective studies are needed, it is unlikely that more frequent colonoscopy will be helpful in CRC patients with FH of colorectal neoplasm, based on the results of our study.

The effect of $\mathrm{FH}$ on improved prognosis of $\mathrm{CRC}$ is sometimes explained by earlier detection of CRC. However, our study only included the patients with same stage, and the baseline patient, disease, and therapeutic factors associated with CRC prognosis such as performance status, depth of invasion, the number of positive lymph nodes, differentiation, preoperative carcinoembryonic antigen, and adjuvant chemotherapy were not different between patients with and without FH. Also, the effect of FH persisted after adjusting for these factors. The protective effect of $\mathrm{FH}$ of colorectal neoplasm on cancer recurrence or mortality in this study was modified by age, depth of invasion, number of positive lymph nodes, tumor location, differentiation, and MSI status. Although tests for interaction were not significant, these factors have a potential to be a mechanism by which $\mathrm{FH}$ affects outcome.

Up to 30\% of CRCs exhibit increased familial risk, but only approximately $5 \%$ of CRCs are associated with highly penetrant, well-defined inherited mutations and clinical presentation, and the etiologies of the remaining 20\% to $30 \%$ of inherited CRCs are not completely understood. Relatively common but less penetrant genetic predisposition may influence survival as well as increased CRC risk in familial CRC patients. Some previous studies suggested that FH of CRC is associated with higher frequency of MSI-high [21], and the beneficial effect of FH on CRC survival was prominent in right colon $[12,15,16]$. However, the association of MSI status on prognosis was not consistent between studies [14], and MSI status was not different by FH in our study. Rather, in this study, stratified analysis showed that the improved OS and DFS was more prominent among patients with left-sided colon and rectal cancer and MSS cancer. Although left side predominance was one of the unique characteristics of Asian HNPCC patients [22], our result suggests that the possible association between a $\mathrm{FH}$ and improved prognosis may be attributed to unrevealed genetic predisposition rather than MSI or MMR status. The linkage analysis and population-based genome-wide association studies have identified a number of potential loci associated with familial CRC, such as 9q22, 8q23, 8q24, 9p24, 11q23, and 18q21 [23,24]. The association of these genetic predisposition and CRC outcome needs to be studied further. However, the relationship between $\mathrm{FH}$ and prognosis of CRC is likely to be complex and may be influenced by an interaction between genetic predispositions and shared environmental factors. Also, it is possible that the mechanism of the influence of $\mathrm{FH}$ on CRC prognosis is different among Asian and Western populations. Further studies are warranted to identify the influence of $\mathrm{FH}$ on prognosis of $\mathrm{CRC}$ and underlying mechanism of increased familial risk and possible improved survival of CRC.

Our study has several strengths. First, because we included 
patients with stage III CRC, the impact of heterogeneity by disease stage can be reduced. Second, long-term follow-up for the survival was available using central data from National Cancer Registry. Third, multiple confounding factors of mortality or adenoma incidence such as smoking, alcohol, BMI, use of aspirin were evaluated and adjusted. Fourth, because the majority of the patients examined the MSI status, the association between MSI status and prognosis could be evaluated.

There were several limitations of this study. First, we collected self-reported $\mathrm{FH}$ on medical records retrospectively, and $\mathrm{FH}$ status may be misclassified or underestimated. Indeed, the sample size of CRC patients with FH of colorectal neoplasm in this study was $8.9 \%$, less than some other studies. However, the Asian studies reported relatively small proportion of $\mathrm{FH}$ compared with Western studies $[25,26]$, and this may be related to the lower incidence of CRC in Asia during previous several decades. Also, self-reported data have been shown to be reliable in the previous studies [27]. To minimize the bias from the self-reported system, we collected multiple medical records containing FH status in the same subject such as admission note, intern note, nurse chart, and colonoscopy results. Second, though we analyzed MSI status, we were unable to evaluate for the other detailed genetic information. Because techniques for genetic analysis including next generation sequencing are developed, it is expected that these tests will be used to link the genes and prognosis related to FH in the near future. Third, this study was a single center, retrospective study, which might lead to bias especially for the surveillance colonoscopy which showed variable number and interval among individuals.

In conclusion, a FH of colorectal neoplasm including CRC and polyps in FDR was associated with a significant reduction in cancer recurrence and mortality in a cohort of patients with stage III CRC treated with surgery. The incidence of adenoma and advanced adenoma on surveillance colonoscopy was not different according to the $\mathrm{FH}$ of colorectal neoplasm in patients with CRC. The protective effect of FH of colorectal neoplasm on cancer recurrence or mortality was modified by age, depth of invasion, number of positive lymph nodes, tumor location, differentiation, and MSI status. The association between a FH and improved prognosis may be attributed to unrevealed genetic predisposition which might have association with these modifying factors. Further studies are warranted to identify the underlying mechanism of increased familial risk and possible association with improved outcome of CRC across different populations.

\section{ACKNOWLEDGMENTS}

This study was supported by a grant from the National R\&D Program for Cancer Control, Ministry of Health and Welfare, Republic of Korea (1631020).

\section{CONFLICTS OF INTEREST}

No potential conflicts of interest were disclosed.

\section{Supplementary Materials}

Supplementary Materials can be found via https://doi.org/ 10.15430/JCP.2019.24.1.1.

\section{REFERENCES}

1. Fuchs CS, Giovannucci EL, Colditz GA, Hunter DJ, Speizer FE, Willett WC. A prospective study of family history and the risk of colorectal cancer. N Engl J Med 1994:331:1669-74.

2. Ramsey SD, Yoon P, Moonesinghe R, Khoury MJ. Populationbased study of the prevalence of family history of cancer: implications for cancer screening and prevention. Genet Med 2006;8:571-5.

3. Johns LE, Houlston RS. A systematic review and meta-analysis of familial colorectal cancer risk. Am J Gastroenterol 2001;96:29923003.

4. Butterworth AS, Higgins JP, Pharoah P. Relative and absolute risk of colorectal cancer for individuals with a family history: a meta-analysis. Eur J Cancer 2006;42:216-27.

5. Slattery ML, Kerber RA. Family history of cancer and colon cancer risk: the Utah Population Database. J Natl Cancer Inst 1994; 86:1618-26.

6. Samadder NJ, Smith KR, Hanson H, Pimentel R, Wong J, Boucher $\mathrm{K}$, et al. Increased risk of colorectal cancer among family members of all ages, regardless of age of index case at diagnosis. Clin Gastroenterol Hepatol 2015;13:2305-11.e1-2.

7. Samadder NJ, Curtin K, Tuohy TM, Rowe KG, Mineau GP, Smith $\mathrm{KR}$, et al. Increased risk of colorectal neoplasia among family members of patients with colorectal cancer: a population-based study in Utah. Gastroenterology 2014;147:814-21.e5; quiz e15-6.

8. Lowery JT, Ahnen DJ, Schroy PC 3rd, Hampel H, Baxter N, Boland $\mathrm{CR}$, et al. Understanding the contribution of family history to colorectal cancer risk and its clinical implications: a state-of-the-science review. Cancer 2016;122:2633-45.

9. Rex DK, Boland CR, Dominitz JA, Giardiello FM, Johnson DA, Kaltenbach $\mathrm{T}$, et al. Colorectal cancer screening: recommendations for physicians and patients from the U.S. multi-society task force on colorectal cancer. Gastroenterology 2017;153: 307-23.

10. Slattery ML, Kerber RA. The impact of family history of colon cancer on survival after diagnosis with colon cancer. Int J Epidemiol 1995;24:888-96. 
11. Phipps AI, Ahnen DJ, Campbell PT, Win AK, Jenkins MA, Lindor NM, et al. Family history of colorectal cancer is not associated with colorectal cancer survival regardless of microsatellite instability status. Cancer Epidemiol Biomarkers Prev 2014;23:1700-4.

12. Jansson-Knodell CL, Foster NR, Sargent DJ, Limburg PJ, Thibodeau SN, Smyrk TC, et al. Family history of colorectal cancer and its impact on survival in patients with resected stage III colon cancer: results from NCCTG Trial N0147 (Alliance). J Gastrointest Oncol 2017;8:1-11.

13. Clinical and pathological analyses of patients with a family history of colorectal cancer. Registry Committee, Japanese Research Society for Cancer of the Colon and Rectum. Jpn J Clin Oncol 1993:23:342-9.

14. Chan JA, Meyerhardt JA, Niedzwiecki D, Hollis D, Saltz LB, Mayer RJ, et al. Association of family history with cancer recurrence and survival among patients with stage III colon cancer. JAMA 2008;299:2515-23.

15. Zell JA, Honda J, Ziogas A, Anton-Culver H. Survival after colorectal cancer diagnosis is associated with colorectal cancer family history. Cancer Epidemiol Biomarkers Prev 2008;17:3134-40.

16. Morris EJ, Penegar S, Whitehouse LE, Quirke P, Finan P, Bishop DT, et al. A retrospective observational study of the relationship between family history and survival from colorectal cancer. $\mathrm{Br} \mathrm{J}$ Cancer 2013;108:1502-7.

17. Schoen RE, Razzak A, Yu KJ, Berndt SI, Firl K, Riley TL, et al. Incidence and mortality of colorectal cancer in individuals with a family history of colorectal cancer. Gastroenterology 2015;149: 1438-45.e1.

18. Bass AJ, Meyerhardt JA, Chan JA, Giovannucci EL, Fuchs CS. Family history and survival after colorectal cancer diagnosis. Cancer 2008; 112:1222-9.

19. Anderson JC, Baron JA, Ahnen DJ, Barry EL, Bostick RM, Burke
CA, et al. Factors associated with shorter colonoscopy surveillance intervals for patients with low-risk colorectal adenomas and effects on outcome. Gastroenterology 2017;152:1933-43.e5.

20. Martínez ME, Sampliner R, Marshall JR, Bhattacharyya AK, Reid ME, Alberts DS. Adenoma characteristics as risk factors for recurrence of advanced adenomas. Gastroenterology 2001;120: 1077-83.

21. Ricciardiello L, Goel A, Mantovani V, Fiorini T, Fossi S, Chang DK, et al. Frequent loss of hMLH1 by promoter hypermethylation leads to microsatellite instability in adenomatous polyps of patients with a single first-degree member affected by colon cancer. Cancer Res 2003;63:787-92.

22. Lee J, Xiao YY, Sun YY, Balderacchi J, Clark B, Desani J, et al. Prevalence and characteristics of hereditary non-polyposis colorectal cancer (HNPCC) syndrome in immigrant Asian colorectal cancer patients. BMC Cancer 2017;17:843.

23. Gray-McGuire C, Guda K, Adrianto I, Lin CP, Natale L, Potter JD, et al. Confirmation of linkage to and localization of familial colon cancer risk haplotype on chromosome 9q22. Cancer Res 2010;70:5409-18.

24. Tenesa A, Dunlop MG. New insights into the aetiology of colorectal cancer from genome-wide association studies. Nat Rev Genet 2009;10:353-8.

25. Lee SD, Kim BC, Han KS, Hong CW, Sohn DK, Park JW, et al. Influence of family history on survival in patients with colon and rectal cancer. J Dig Dis 2014;15:108-15.

26. Yuan Y, Li MD, Hu HG, Dong CX, Chen JQ, Li XF, et al. Prognostic and survival analysis of 837 Chinese colorectal cancer patients. World J Gastroenterol 2013;19:2650-9.

27. Kerber RA, Slattery ML. Comparison of self-reported and database-linked family history of cancer data in a case-control study. Am J Epidemiol 1997;146:244-8. 